\title{
Deficiency symptoms in cacao seedlings observed in pot experiments with the Bouma-Janssen method
}

A. Muller

Department of Agricultural Research, Royal Tropical Institute, 1092 AD Amsterdam, the Netherlands

Accepted: 12 January 1979

Key words: deficiency, cacao, volcanic ash soil, Ecuador, pot experiment

\section{Summary}

The so-called Bouma-Janssen pot experiment method with a double pot technique was used to show deficiency symptoms in tropical perennial crops. Cacao was used as test plant with purified sand and with a volcanic ash subsoil from Ecuador as the growing medium in the upper pots. The deficiency symptoms observed agreed in general well with those described by other workers; however, with the present experiment the symptoms appeared in a much earlier stage than reported in experiments with conventional sand or water cultures.

Sickle leaf has usually been related to zinc deficiency, but other nutrient disorders may produce sickle leaf as well, as was the case with the boron deficiency in the present study.

\section{Introduction}

In the early 1970 s a new method for testing soil fertility was developed by Janssen $(1970,1973,1974)$, based on previous studies by Bouma $(1965,1967)$. The method was preliminarily tested by Muller (1974a) on its suitability for exper-, iments with tropical percennial crops such as cacao; he called the technique the 'Bouma-Janssen method'. Later a more detailed study was carried out by Muller (1947b).

The Bouma-Janssen (B-J) method uses a combination of two pots. The upper pot has a perforated bottom and is filled with the test soil. Seeds, germinating seeds or small seedlings are planted in this soil. The lower pot is filled with demineralized water in the first stage of the experiment. When in all pots of the experiment roots have penetrated through the bottom of the upper pot, the lower pot is filled with a nutrient solution of a specific composition. If, for example, the lower pot is filled with a nutrient solution only deficient in nitrogen, but the test soil contains a fair amount of this element, the growth of the seedling will 
scarcely be affected. However, if both the test soil and nutrient solution are deficient in nitrogen, plant growth will be severely affected. The effect of fixation of phosphate, potassium and ammonium, of lack of nitrification, $\mathrm{pH}$, and other factors which might give complications in the conventional techniques where nutrientsc are added to the soil is avoided with this method.

In this paper the deficiency symptoms observed by Muller (1974b), together with those of two additional experiments, are described and illustrated. The observations are compared with those of other authors who worked with cacao but used conventional sand or water culture techniques.

\section{Materials and methods}

The test soil was a volcanic ash subsoil from Ecuador. Results of the soil analysis are presented in Table 1.

Two experiments were carried out. In the first experiment seeds were used from cacao clone DR 38 of Sumatra to test the effect of the absence of $\mathbf{N}, \mathrm{P}, \mathrm{K}$, $\mathrm{Ca}, \mathrm{Mg}$ or $\mathrm{B}$ in the nutrient solution in the lower pot. There were two pots per treatment with one plant per pot. Results of this experiment have been reported in detail in an earlier publication (Muller, 1974b).

In the second experiment seeds were used of an ICS clone of Surinam to test the effect of the absence of $\mathrm{S}, \mathrm{Fe}, \mathrm{Mn}, \mathrm{Zn}, \mathrm{Cu}$ or Mo. To check both the major and minor element deficiency symptoms, a parallel series was taken along with purified sand in the upper pots instead of volcanic ash subsoil. The $-\mathrm{N},-\mathrm{P},-\mathrm{K}$, $-\mathrm{Ca}$ and $-\mathrm{Mg}$ treatments were discontinued after 12 weeks. As during this period no specific visual symptoms could be observed in the micro-element treatments, these were continued for another 8 weeks.

For the description of colours, colour names and codes are used according to the Japanese Standard Colour Charts (Kiuchi et al., 1972).

From the results of soil analyses strong deficiency symptoms were expected for $-\mathbf{N},-\mathrm{Ca},-\mathrm{Mg},-\mathrm{K},-\mathrm{Fe}$ and $-\mathrm{Mn}$. Phosphate deficiency was not expected; in normal mineral non-volcanic ash soils an Olsen value of $49 \mathrm{mg} / \mathrm{kg} \mathrm{P}_{2} \mathrm{O}_{5}$ is

Table 1. Some properties of a volcanic ash subsoil from Ecuador.

\begin{tabular}{|c|c|c|c|}
\hline $\mathrm{pH}-\mathrm{H}_{2} \mathrm{O}(1: 2.5)$ & 6.2 & $0.6 \mathrm{~N} \mathrm{BaCl} 2$ & \\
\hline $\mathrm{pH}-\mathrm{KCl}(1: 2.5)$ & 5.1 & exchangeable cations & \\
\hline $\mathrm{pH}-0.6 \mathrm{~N} \mathrm{BaCl}{ }_{2}$ & 4.2 & $\mathrm{meq} / 100 \mathrm{~g} \mathrm{Ca}$ & 0.89 \\
\hline$\% \mathrm{C}$ (Wakley and & & $\mathrm{Mg}$ & 0.11 \\
\hline Black) & 0.81 & $\mathbf{K}$ & 0.18 \\
\hline$\% \mathrm{~N}$ (Kjeldahl) & 0.11 & $\mathrm{Na}$ & 0.23 \\
\hline \multirow[t]{2}{*}{$\mathrm{P}$-Olsen, $\mathrm{mg} \mathrm{P}_{2} \mathrm{O}_{5} / \mathrm{kg}$} & 49 & $\mathrm{Al}$ & 0.41 \\
\hline & & $\mathrm{Fe}$ & 0 \\
\hline $\mathrm{NH}_{4}$-acetate $\mathrm{pH}$ & & Mn & $\mathbf{0}$ \\
\hline 4.8 extractable & & Total cations & 1.8 \\
\hline $\mathrm{NO}_{3}, \mathrm{mg} / \mathrm{kg}$ & 35 & Unbuffered CEC, meq/100 g & 1.6 \\
\hline $\mathrm{SO}_{4}, \mathrm{mg} / \mathrm{kg}$ & 39 & CEC pH 8.2 & \\
\hline $\mathrm{Cl}, \mathrm{mg} / \mathrm{kg}$ & 10 & $\mathrm{meq} / 100 \mathrm{~g}$ & 14.2 \\
\hline
\end{tabular}


considered as adequate. Apparently the Olsen method is less suitable for the analysis of available $\mathbf{P}$ in volcanic ash soil because the $-\mathrm{P}$ treatment showed strong deficiency symptoms.

\section{Deficiency symptoms}

\section{Nitrogen deficiency}

Nitrogen deficiency was characterized by strongly reduced growth which became visible after the second week of the experiment.

The leaves matured rapidly and consequently remained small. The full-grown leaves were chlorotic of an uniformly soft yellow-green colour (5GY 7/5). In Plate 1a a healthy full-grown leaf and a healthy young leaf are shown whereas in Plate 1b full-grown leaves are shown of a nitrogen-deficient plant of the same age as the healthy plant (complete treatment). In the nitrogen-deficient plants the oldest leaves of the same flush became necrotic at the terminal part of the leaf during the last weeks whereas the young developing leaves were almost white. During the 12 weeks of the experiment no defoliation occurred, but in the last week the leaf primordia desiccated.

The symptoms agreed well with those found in earlier studies by Mac Donald (1934), Maskell et al. (1953), Evans \& Murray (1953), Machicado \& Alvim (1954), Lockard et al. (1959) and Loué (1961). These authors working with sand or water cultures reported that the visual symptoms began to show 8-13 weeks after initiation of treatments.

In the parallel experiment with purified sand, the first symptoms were observed later than in the volcanic ash series, viz after 14 weeks. Before that period the $-\mathrm{N}$ plants showed a growth comparable to that of the plants of the complete treatment; the leaves of the $-\mathrm{N}$ plants which ultimately became chlorotic were much larger than those of the $-\mathrm{N}$ treatments in the volcanic ash series.

\section{Phosphate deficiency}

In the volcanic ash series, the first symptoms of phosphate deficiency were observed between the 5 th and the 8th week, starting with the least vigorous plant of the two -P treatments, which already after 4 weeks showed a reduction in growth of $40 \%$ compared with the plants of the complete treatment (Muller, 1974b).

The young and full-grown leaves of the last flush were smaller with a higher value for the length/width ratio than the corresponding leaves of the 'complete' plants, but the colour was normal. However, the older leaves of the preceeding flush showed a blotchy appearance due to loss of colour between the veins as described by Maskell et al. (1953). These older leaves became also necrotic, usually starting from the tip. The necrosis proceeded towards the base of the leaves. There was a sharp boundary between the necrotic tissue and the rest of the leaf lamina which showed a diffuse interveinal chlorosis.

Finally the strongly affected leaves were shed. In some cases the necrosis started in the more central parts of the leaves, usually preceeded by a grayish 
purple discolouration (2.5 RP 3/2). Plate 1c shows the various stages of development of phosphate deficiency symptoms.

The deficiency symptoms for $P$ as reported by other workers became visible much later than those in the present experiment with volcanic ash subsoil.

Loué (1961) working with water cultures, observed the first symptoms only after 7 months, Mac Donald (1935) found that in sand cultures the plants of the $-\mathrm{P}$ treatment remained normal even after 10 months, whereas Machicado \& Alvim (1954) reported strong leaf fall only in a very advanced stage of phosphate deficiency. Also, the descriptions of the different authors show variations.

The findings in the present experiment were more or less in agreement with those of Maskell et al. (1953) and Loué (1961).

In the parallel sand series almost the same symptoms were observed as described by Loué, but they appeared already after 10 weeks.

\section{Potassium deficiency}

In the plants of the $-\mathrm{K}$ treatments in the volcanic ash series, there was practically no growth during the third and fourth week of the experiment. During the fifth week growth started again, but visual deficiency symptoms developed. The leaves of the last flush had a normal colour but the length/width ratio was larger than for the leaves of the complete treatment. In the leaves of the older flushes various symptoms were observed. Some leaves had the same blotchy appearance as described for the initial symptoms of phosphate deficiency, but the loss of colour between the veins was less pronounced. Other leaves showed a distinct dull reddish discolouration (10YR $8 / 7$ ) along the midrib. The pattern was broader at the base of the leaf and tapered off towards the tip (Plate $1 \mathrm{~d}$, second leaf from left). This discolouration was accompanied by small dull reddish yellow spots in the network of veins, some of the lateral veins also being dull reddish yellow (10YR 8/6). The typical yellowing along the midrib shown in Plate $1 \mathrm{~d}$. was also mentioned by Loué (1953). In other leaves the midrib remained olive green (5GY 4.5/6) with larger patches of dull reddish yellow between the lateral veins (Plate 1d, third leaf from left). At a more advanced stage these patches coalesced and became necrotic.

\section{Plate 1.}

a (top left): leaves of a healthy cacao seedling (complete treatment).

b (top right): leaves of a nitrogen-deficient plant; left a young full-grown leaf, centre and right older leaves of the same flush with necrosis starting from the tip.

c (middle left): leaves of a phosphor-deficient plant, symptoms of various stages of phosphor deficiency.

d (middle right): leaves of a potassium-deficient plant showing various symptoms of potassium deficiency.

e (bottom left): leaves of a calcium-deficient plant showing early stages of calcium deficiency. $f$ (bottom right): leaves of a magnesium-deficient plant; left and centre initial stages of magnesium deficiency, right a more advanced stage. 


$$
\begin{aligned}
& 10100 \\
& 0000000 \\
& 000010
\end{aligned}
$$



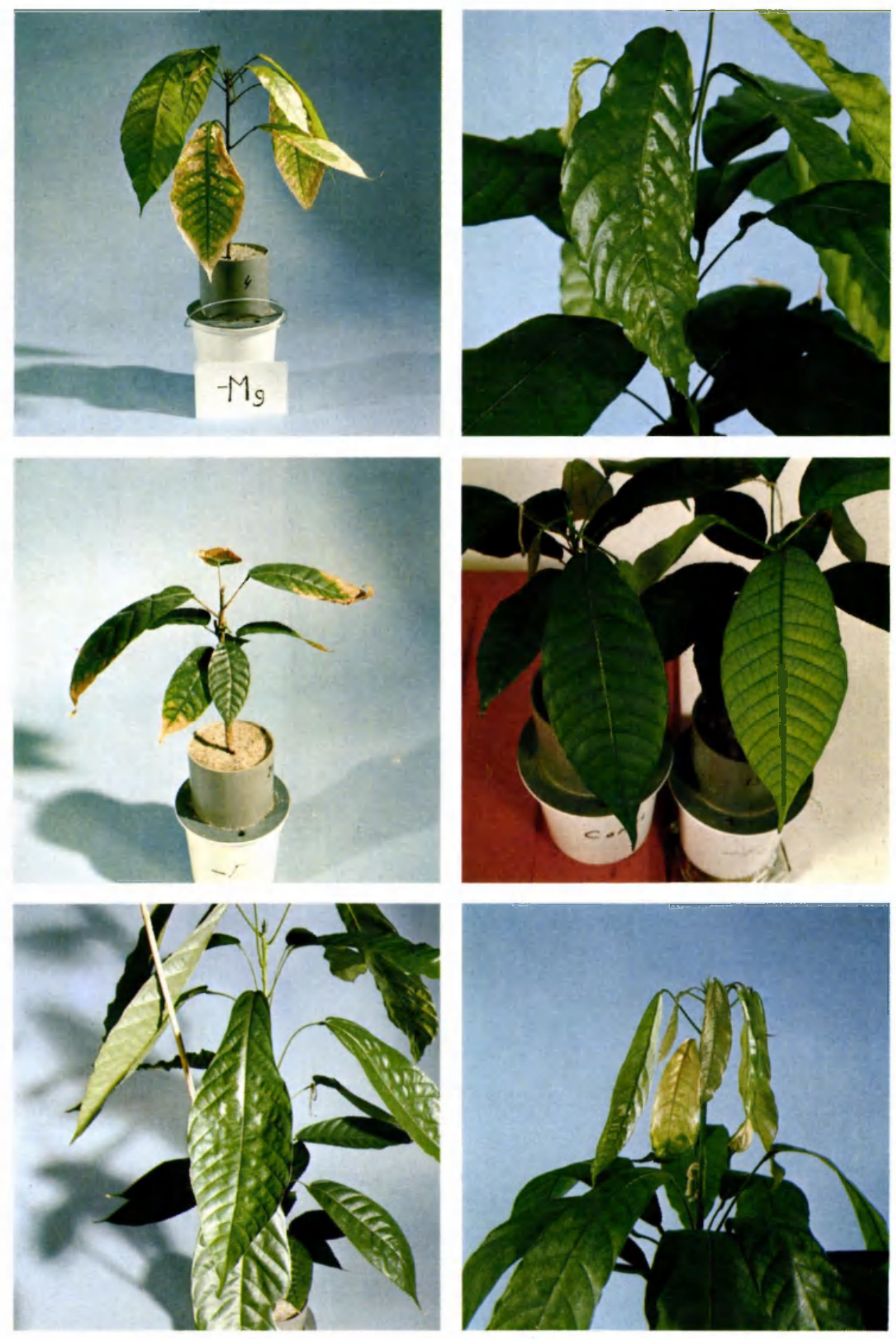
The necrosis usually started at the tip of the leaves and along the margin, but it occurred also in the more central parts of the leaves. In cases where midrib and veins remained greenish, the necrotic tissue was bordered by an area of an undulating or zigzag pattern of dull reddish yellow. This area may reach the greenish veins, particularly at the upper half of the leaf, or may exist as a narrow band of a few millimetres wide as also described by Maskell et al. (1953) (see Plate 1d, fourth leaf from left).

As mentioned before, the initial symptoms of potassium deficiency resemble the initial symptoms of phosphate deficiency, but the undulating or zigzag borderline typical for advanced potassium deficiency is quite different from advanced phosphate deficiency where there is a sharp boundary between the necrotic and the still greenish tissue.

Ultimately, the whole leaf became necrotic and was dropped, but shedding of leaves occurred also at an earlier stage.

\section{Calcium deficiency}

Between the second and the fifth week, there was practically no growth in the plants of the $-\mathrm{Ca}$ treatment. After 6 weeks the plants started to grow again but at a very slow rate. One of the duplicates did not grow from the 7 th week till the 10 th week after which it regained growth, but the 2 nd plant stopped growing completely after the 8 th week.

The leaves of the plant reached very rapidly their ultimate size and consequently remained small as was the case with the plants of the $-\mathbf{N}$ treatment, but the colour was strong yellow green (5GY 6/8). In the full-grown leaves of the last flush a number of white spots could be observed particularly when the leaves were held against the light. These spots were most abundant on the upper part of the leaves and along the margin. The leaf tip was necrotic (see Plate 1e). In a later stage these white spots turn to a dull reddish yellow colour (10YR 8/8) and may coalesce, usually combined with increased top and marginal necrosis in the same manner as described by Maskell et al. (1953) and Loué (1961). However, during the 12 weeks of the experiment, the more intense yellow spotting as mentioned by Loue (1961) and the more advanced marginal necrosis 'leaving an oak-leaved pattern of unaffected lamina' as described by Maskell et al. (1953) were not observed, neither in the volcanic ash nor in the sand series.

\section{Plate 2.}

a (top left): advanced stage of magnesium deficiency (sand series).

b (top right): sickle leaf produced by a boron-deficient plant.

c (middle left): boron-deficient plant of the sand series with desiccated top, distorted side shoots and necrotic leaf.

d (middle right): right iron-deficient cacao seedling, left healthy plant.

e (bottom left): zinc-deficient plant with 'pear-shaped' and 'corrugated' leaves.

f (bottom right): close-up of the top of a copper-deficient cacao seedling. 


\section{Magnesium deficiency}

Till the fifth week, the growth of the $-\mathrm{Mg}$ plants seemed to be faster than that of the complete treatment, but afer seven weeks reduction of growth became apparent. The first deficiency symptoms became visible after five weeks in the leaves of the older flushes. In the oldest leaf of the second flush after germination the first symptoms became visible as a faint interveinal chlorosis between the lateral veins accompanied by small blackish pinpoints. These points were sometimes evenly distributed over the leaf surface but in other cases concentrated in different parts of the leaf blade. In a later stage, around these blackish spots the chlorosis became more intense so that the leaves were dotted with dull reddish yellow spots (10YR 8/7) with a blackish centre (Plate 1f, left and centre leaf). These dull reddish yellow spots coalesced, usually towards the leaf tip and the leaf margin from where necrosis started (Plate 1f, third leaf from left). The tip and marginal necrosis were not always as continuous as described by Maskell et al. (1953). In cases where the initial blackish spots were concentrated in specific parts of the leaf lamina, yellowing and necrosis started in that section. The necrotic tissue alternated with patches of still greenish tissue, giving the leaf a blotchy or 'marbled' appearance. Ultimately the whole leaf became necrotic; the blotchy appearance remained present because a brown colour (5YR 4/5) alternated with a light yellowish brown colour (7.5YR 6/8). Usually, before this stage the affected leaves were already shed.

In the sand series, the magnesium deficiency was more acute than in the volcanic ash series. Also the younger leaves, even of the latest flush, were afected before they were full-grown. As described by Maskell et al. (1953) tip and marginal necrosis were more continuous than in the volcanic ash series. Plate 2 a shows a leaf of an acutely magnesium-deficient plant where the necrotic tissue was almost white against which the still green veins stood out as ribs of a human skeleton' as Maskell et al. have described it so adequately.

\section{Sulphur deficiency}

Only after 14 weeks a faint chlorosis became visible in one of the $-S$ plants in the volcanic ash series. After 17 weeks the three last-matured leaves were uniformly chlorotic varying in colour from strong yellow green (5GY 6.5/8) in the youngest of the three leaves to soft yellow green $(5 G Y 9 / 4)$ in the other leaves. The internode of the last flush was very short. The older leaves of the previous flushes had a patchy appearance due to interveinal chlorosis, whereas in some leaves tip or marginal chlorosis occurred. In the other plant of the volcanic ash series and the plants of the sand series symptoms became visible after 20 weeks. General necrosis of older leaves or tips and marginal necrosis as reported by Loué (1961), Machicado et al. (1954), and Maskell et al. (1953) were not observed.

\section{Boron deficiency}

Till the twelfth week no specific symptoms except for reduction in growth, a very short internode of the last flush and a strongly retarded new flush, could be observed in the plants of the $-\mathrm{B}$ treatment, growing in volcanic ash soil. After 

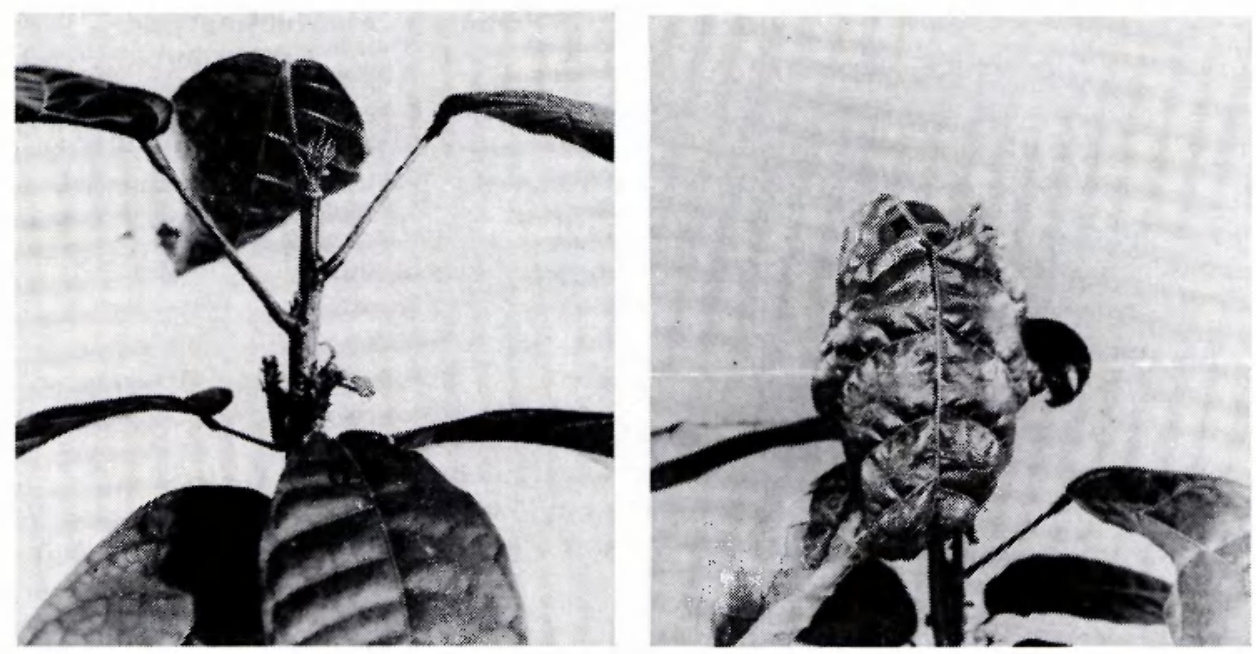

Fig. 1. a (left): close-up of the top of a boron-deficient plant with distorted side shoots. b: distorted leaf of a boron-deficient plant.

sixteen weeks the new flush developed strongly curved leaves known as 'sickle leaf' (see Plate 2b).

In the plants growing in purified sand, boron deficiency was more acute. One of the duplicates stopped growing after 4 weeks. The leaf primordia desiccated except for one which produced a strongly distorted leaf which became soon necrotic (Plate 2c). The 2 nd plant kept growing but at a very slow rate. The top desiccated, but the plant tried to produce side shoots in the axils of the upper leaves. It only succeeded to do so after 16 weeks (see Fig. 1a). The produced leaves were strongly distorted, sharply curved backwards, hardening when still small and feeling hard to the touch (see Fig. 1b).

\section{Manganese deficiency}

The only symptom which indicated suboptimal nutrition of the plants of the -Mn treatment was that some leaves had an 'inverted boat' form, whereas in other leaves only the margin at the basal part was curved downwards. The diffuse but distinct interveinal chlorosis and pale colour of the young leaves, followed by tip and marginal chlorosis, as described by Loué (1961) were not observed.

\section{Iron deficiency}

In the volcanic ash series reduction of growth started after six weeks, but already after four weeks the first symptoms of chlorosis appeared in the mature leaves of the first flush. These symptoms became more intense after six weeks. The mature leaves of the next flushes were also affected. They were characterized by a dull yellow green colour (5GY 6/7) of the lamina against which the still dull green 
(7.5GY 4/6) veins were sharply outlined (see Plate $2 \mathrm{~d}$ ). The leaf surface had a corrugated appearance due to the convex shape of the parts between the lateral veins. At the margin convexing was more pronounced, giving the leaves a slightly dentated look. However, deep indentation and other deformations as described by Maskell et al. (1953) were not observed. In one of the duplicates of the volcanic ash series, half of the surface of an initially chlorotic leaf became green again, the still chlorotic and the green part being divided by the midrib.

\section{Zinc deficiency}

In some leaves of the first flush, zinc deficiency became visible soon after the start of the experiment. The affected leaves were as large as the corresponding leaves of the plants of the complete treatment, but they showed a distinct 'waist' as Maskell et al. (1953) described for the intermediate range of zinc deficiency, resulting in an elongated pear-shaped form. Such leaves were also shown in the publication of Loué (1961).

However, in the subsequent flushes these leaves were not always present. Large normal leaves were formed which only had a corrugated appearance due to 'arching of the interveinal spaces into folds, convex to the upper leaf surface' (Greenwood \& Djokoto, 1952). This corrugation of the leaf surface was much stronger than in the case of iron deficiency (see Plate 2e).

In the sand series more malformed leaves were present, some slightly 'sickle shaped'.

\section{Copper deficiency}

For 12 weeks specific symptoms could neither be observed in the plants of the $-\mathrm{Cu}$ treatment in the volcanic ash series, nor in the sand series. However, after 17 weeks young leaves of the last flush which were less than $5 \mathrm{~cm}$ long wilted overnight and were dropped before hardening. The leaves which were longer than $5 \mathrm{~cm}$ showed a strong chlorosis. This chlorosis started from the top part of the leaf which became almost white, but the affected leaves were dropped before they became necrotic. One of the plants did not produce new leaves after the leaflets were shed, the other plants succeeded to form new leaves which had a strong turgidity, but they remained slender. The older of these leaves showed top chlorosis, partly turning to an almost white colour, the chlorotic area 'forming a wedge directed towards the midrib from the top of the leaf' (Maskell et al. 1953), and shown in the publication by Lockard et al. (1959). The chlorotic area became necrotic before the leaf was dropped. Specific symptoms are shown in Plate $2 \mathrm{f}$.

\section{Molybdenum deficiency}

Even after 20 weeks, none of the symptoms described by Lockard et al. (1959) and Maskell et al. (1953) for Mo deficiency could be observed. The only indication of suboptimal molybdenum nutrition was the undulating aspect of the leaves as described for iron deficiency and a slight torsion of the top part of young and mature leaves.

Apparently, molybdenum is not an essential element for young cacao seedlings. 
According to Lockard et al. (1959) molybdenum deficiency appeared in their experiment when the plants were 279 days old.

\section{Discussion and conclusion}

The deficiency symptoms in cacao seedlings as observed in the current experiment agreed in general well with those described by other workers. However, test soil, method of experimentation and also cultivar apparently have an influence on the initiation and development of deficiency symptoms. This was particularly so for the $-\mathrm{N}$ treatments where nitrogen deficiency was observed much earlier in the volcanic ash series than in the sand series. Apparently, beside nitrogen deficiency in the volcanic ash subsoil, there are other properties which also influence the development of the cacao seedlings.

Also in the case of phosphate there was a large difference in time of initiation of deficiency symptoms between the volcanic ash and the sand series. But also in the B-J sand series phosphate deficiency was observed much earlier (after 10 weeks) than in the conventional sand culture of Mac Donald (1935) who stated that the plants of the $-P$ treatment remained normal even after 10 months.

In the case of calcium, the -Ca plants in the sand series did not show the symptoms of extreme calcium deficiency as described by Maskell et al. (1953). Though the sand was purified by $\mathrm{HCl}$ treatment followed by repeated washings with demineralized water it may still have contained some calcium.

Sickle leaf has usually been related to zinc deficiency (Greenwood \& Hayfron, 1951; Schroo, 1959) but, as also stated by Maskell et al. (1953) and Loué (1961), a sickle leaf is by no means a universal feature of zinc deficiency. Other nutrient disorders may produce sickle leaf as well, as was the case with the boron deficiency in the present study.

\section{Acknowledgment}

Thanks are due to Mr J. W. Voskuilen, technician who fabricated the B-J pots, and to the Central Bureau for Photo Documentation of the Royal Tropical Institute for taking the colour slides. The financial support of the Royal Tropical Institute enabling the printing of the colour photographs is gratefully acknowledged.

\section{References}

Bouma, D., 1965. Growth changes of plants following the removal of nutritional stresses. Thesis, Agricultural University, Wageningen, Netherlands.

Bouma, D., 1967. Growth changes of subterranean clover during recovery from phosphorus and sulphur stresses. Aust. J. biol. Sci. 20: 51-66.

Evans, H. \& D. B. Murray, 1953. A colour-illustrated guide to the diagnosis of mineral deficiencies in cacao. A report of cacao research 1945-1951. Imperial College of Tropical Agriculture, Trinidad, p. 65-66.

Greenwood, M. \& R. K. Djokoto, 1952. Symptoms of mineral deficiencies in cacao. J. hort. Sci. 28 (4) 223-236. 
Greenwood, M. \& R. J. Hayfron, 1951. Iron and zinc deficiencies in cacao in the Gold Coast. Emp. J. exp. Agric. 19 (74) 73-86.

Kiuchi, T., F. Yazawa \& T. Hirai, 1972. Standard leaf colour charts. National Institute of Agricultural Science, Japan.

Janssen, B. H., 1970. Soil fertility in the Great Konya Basin, Turkey. Agric. Res. Rep. 750. Pudoc, Wageningen, Netherlands.

Janssen, B. H., 1973a. Een oriënterend onderzoek naar de geschiktheid van maïs voor de bepaling van het sufficiency quotient (SQ). Celos rapp. No 76, Paramaribo, Suriname. (Restr. publ.)

Janssen, B. H., 1973b. A study on the nutritional status of Pinus caribea Morelet by means of the technique used for the assessment of sufficiency quotients. Celos Bull. 18 and 49, Paramaribo, Suriname.

Janssen, B. H., 1974. A double pot technique for rapid soil testing. Trop. Agric., Trinidad 51 (2) 161-166.

Loué, A., 1961. Etudes des carences et des deficiences minérales sur le cacaoyer. Bull. Inst. Fr. Café Cacao No 1.

Lockard, R. G., P. Vanathevan \& S. Tahmboo, 1959. Mineral deficiency symptoms of cacao growing in sand culture. Bull. Dep. Agric., Fedn Malaya No 107.

Mac Donald, J. A., 1935. Some effects of deficiencies of essential nutrient elements on the growth of young cacao plants. Imperial College of Tropical Agriculture, Trinidad, p. 83-87.

Machicado, M., \& P. de T. Alvim, 1954. Sintomatologia de las deficiencias minerales de cacao. Turrialba 4 (3-4).

Maskell, E. J., H. Evans \& D. B. Murray, 1953. The symptoms of nutritional deficiencies in cacao produced in sand and water cultures. A report on cacao research 1945-1951. Imperial College of Tropical Agriculture, Trinidad, p. 53-64.

Muller, A., 1974a. A preliminary experiment to test the 'Bouma-Janssen method' with perennials. Bull. Dep. agric. Res., Royal trop. Inst., Amsterdam No 297.

Muller, A., 1974b. Nutrient deficiencies in a volcanic ash soil from Ecuador. Proc. 7 th int. Coll. Pl. An. Fert. Probl. (Hannover, FRG) 343-341. 